\title{
A NARRATIVA TRANSMÍDIA NO PROCESSO DE ENSINO E
} APRENDIZAGEM DE ADOLESCENTES

\author{
THE TRANSMIDIA STORYTELLING IN THE TEACHING AND \\ LEARNING PROCESS OF ADOLESCENTS ${ }^{1}$
}

\author{
Alboni Marisa Dudeque Pianovski Vieira \\ Doutora em Educação pela Pontifícia Universidade Católica do Paraná. \\ Professora do Programa de Pós-Graduação em Educação da Pontifí- \\ cia Universidade Católica do Paraná. Curitiba, PR - Brasil \\ ORCID: https://orcid.org/0000-0003-3759-0377 \\ alboni@alboni.com \\ Ana Cristina Munaro \\ Doutoranda em Administração pela Pontifícia Universidade Católica do Paraná \\ Programa de Pós-Graduação em Administração (PPAD) PUCPR, Curitiba, PR - Brasil \\ ORCID: https://orcid.org/0000-0002-5973-0142 \\ acmunaro@gmail.com
}

\begin{abstract}
Resumo: $\mathrm{O}$ uso de histórias combinado com as tecnologias de informaçáo e comunicação pode ser uma soluçáo para integrar professores e alunos no processo de ensino e aprendizagem, de forma a desenvolver e compartilhar o conteúdo com maior efetividade. O estudo faz uma revisão bibliográfica para verificar a efetividade do uso da estratégia da narrativa transmídia para o engajamento de adolescentes nesse processo. A pesquisa buscou nas bases de dados da Web of Science e Periódicos Capes os artigos da área de Educação, sem delimitação de língua, com os termos: narrativas transmídia na educação, transmídia storytelling e aprendizado transmídia. Como resultados, nota-se que muitos dos estudos são exploratórios; percebem-se certos equívocos na implantaçâo da narrativa transmídia em sala de aula, utilizando-se, muitas vezes, as narrativas dissociadas da comunicação transmídia; a metodologia também vem sido implantada de forma complementar com o ensino por estudos de caso e por resolução de problemas. Mesmo assim, o uso de narrativa transmídia na educação consegue engajar os docentes e parece ser bem efetivo para o aprendizado.
\end{abstract}

Palavras-chave: Engajamento. Ensino-aprendizagem. Narrativa transmídia.

Aвstract: The use of stories combined with communication and information technologies can be a solution to bring together teachers and students in the processes of teaching and learning, with a view to exploring and sharing the content more effectively. The study carried out a literature review to verify the effectiveness of using transmedia storytelling in the teaching and learning process. The results showed that many of the studies carried out have been exploratory, and as such, certain mistakes can be seen in the implementation of transmedia storytelling in the classroom, including the frequent 
use of stories not connected to transmedia communication. The methodology has also been employed to complement teaching based on case studies and problem solving. Even so, the use of transmedia storytelling in education does engage teachers and appears to be effective for learning.

KeYwords: Engagement. Teaching-learning. Transmedia Storytelling.

\section{Introdução}

O processo de ensino e aprendizagem tem se tornado um desafio nas escolas, entre outros motivos, devido à onipresença das tecnologias de informação e comunicação que póe em cheque o modelo tradicional de ensino e fornece oportunidades de trabalho com metodologias ativas que permitem melhor acompanhamento e avaliaçáo desse processo. $\mathrm{Na}$ era digital, os educadores são confrontados com perturbaçôes significativas: um panorama midiático em mudança; a ruptura com as formas tradicionais de entregar instrução; um desenvolvimento rápido das tecnologias móveis e o impacto inerente no contexto educacional. No entanto, essa nova era trouxe possibilidades sem precedentes para desenvolver aprendizagem e numerosas formas de projetar experiências de aprendizagem (RODRIGUES; BIDARRA, 2014).

Essas possibilidades estão ligadas ao fato de que os adolescentes de hoje pertencem à chamada Geração $\mathrm{Z}$ (o $\mathrm{Z}$ da nomenclatura vem do verbo zapear), situam-se na faixa etária de 12 a 19 anos e sabem lidar com a tecnologia, explorando com eficiência a mídia e suas ferramentas de transmissão de informaçóes. Acessam a internet, falam ao celular, ouvem música, fazem o dever de casa, leem revista e assistem televisão, quase de forma simultânea (TAPSCOTT, 2010). Levam esse comportamento, em ritmo fragmentado e acelerado, para as escolas e empresas em que trabalham, exigindo novas práticas educacionais e gerenciais (CERETTA; FROEMMING, 2011).

Jenkins et al. (2009) denominaram esse processo de cultura participativa, correspondendo à forma como a cultura absorve e responde à presença aumentada de novas tecnologias de mídia na vida social, tornando possível aos indivíduos arquivar, anotar, adequar e ressaltar o conteúdo da mídia de maneiras novas e influentes. Cada participante pode navegar em modos diferentes, que lhe permitam fazer escolhas sobre as melhores ma- 
neiras de expressar as suas ideias em cada contexto (KRESS, 2003). A mediação da aprendizagem, dessa forma, se transforma: os alunos expressam suas opiniôes por meio de ferramentas de criaçáo de conteúdo e as compartilham em um ambiente de rede; a mobilidade e o desenvolvimento de smartphones, bem como a utilização da realidade aumentada, trouxeram uma nova dimensão: a integração do mundo digital com o mundo físico (RODRIGUES; BIDARRA, 2014).

Nesse cenário, a narrativa transmídia refere-se às experiências de mídia integradas que ocorrem por uma variedade de plataformas. Para Rodrigues e Bidarra (2014), contar histórias é considerada uma atividade humana inata, um elemento central da comunicação humana e da produção de sentido, que aprimora o desenvolvimento individual e implica, também, um sentido de identidade cultural. Segundo Gambarato (2013), a narrativa transmídia diz respeito a uma grande história difundida, atraindo o engajamento do público: náo se trata de oferecer o mesmo conteúdo em diferentes plataformas de mídia, mas, sim, de uma experiência de construção de mundo, com a manifestação do conteúdo em mídias integradas, gerando possibilidades para uma história evoluir com conteúdo novo e pertinente. Kalogeras (2013) faz uso do conceito de narrativa transmídia (transmedia storytelling) de entretenimento educativo (TmSE), que é definida como a utilização de histórias de entretenimento popular para criar componentes educacionais em torno de uma disciplina. Entende que qualquer coisa que ajude o público com diferentes estilos de aprendizagem só pode ser benéfica, afirmação que ainda demanda pesquisas.

No entanto, parece que um roteiro consegue deixar os alunos mais envolvidos com o trabalho, os estudantes preferem uma história em lugar de um livro, porque é mais envolvente e parece promover uma melhor retenção. Para Raybourn (2014), a aprendizagem transmídia é definida como o sistema escalável de mensagens representando uma narrativa ou núcleo de uma experiência que se desenrola no uso de múltiplas mídias, engajando os alunos emocionalmente no aprendizado, envolvendo-os pessoalmente na história. Conforme Fitzgibbon e Wilhelm (1998), os defensores da narrativa como uma ferramenta pedagógica afirmam haver muitas vantagens em sua utilização. Contudo, poucos estudos podem ser encontrados que rigorosamente apoiem os supostos benefícios de contar histórias. Assim, esta pesquisa visa a responder: qual é a efetividade do 
uso da estratégia de ensino com narrativa transmídia no engajamento de adolescentes em sala de aula? A pesquisa tem por objetivo geral analisar o impacto do uso da estratégia de narrativa transmídia para o engajamento de adolescentes no processo de ensino-aprendizagem. Como objetivos específicos, adotam-se: identificar como está sendo implantada a estrutura de narrativa transmídia em sala de aula e levantar dados do engajamento dos alunos no uso da narrativa transmídia para o aprendizado em sala de aula.

O trabalho está estruturado da seguinte forma: a primeira seção é introdutória; segue a seção que apresenta o referencial teórico, por sua vez centrado no conceito de narrativa transmídia, em elementos de sua história, nos estudos acadêmicos da metodologia narrativa no processo de ensino-aprendizagem e na variável do engajamento dos estudantes por exposição à narrativa transmídia; a terceira seção traz discussóes e análises em torno dos estudos empíricos abordados na pesquisa, para, por fim, tecerem-se as consideraçôes finais, apontando os limites das atuais pesquisas e as propostas para futuras investigaçóes.

\section{Referencial teórico}

A alfabetização transmídia ainda é escassa e voltada principalmente para aspectos instrumentais e tecnológicos. Del Mar Grandio-Perez (2016) afirma que, apesar da crescente literatura sobre narrativas transmídia disponíveis, sente-se a ausência de uma literatura de formação adequada em transmídia. Uma vez que a pedagogia transmidiática permite que os alunos e o conteúdo ganhem fluidez através das plataformas de mídia. Dessa forma, transcender o conteúdo permite o compartilhamento colaborativo e a proliferação de conhecimento em todo o mundo (FLEMING, 2013).

Nesse sentido, o referencial teórico aborda alguns dos principais conceitos sobre narrativas transmídia na educação, apresentando sua origem (2.1), as características majoritárias desse modelo de ensino e suas contribuiçóes para o engajamento no processo de ensino-aprendizagem de adolescentes (2.1.1). Além disso, é discutido o perfil da geração $Z$ de adolescentes no processo de aprendizagem (2.2). 


\subsection{Narrativa transmídia}

Marsha Kinder foi quem criou o termo transmídia em seu livro intitulado Playing with Power in Movies, Television and Video Games, de 1991 (KINDER, 1991). Anos mais tarde, Henry Jenkins, então professor no Massachusetts Institute of Technology (MIT), publicou um artigo, intitulado Transmedia storytelling, que ampliou os conceitos envolvidos nessa forma de comunicação e o tornou, até hoje, uma das maiores referências em pesquisa sobre mídia no mundo.

Uma narrativa transmídia (transmedia storytelling) desenrola-se por meio de múltiplas plataformas de mídia, com cada novo texto contribuindo de maneira distinta e valiosa para o todo, representa uma nova espécie de relaçáo entre os receptores, pautada na convergência de plataformas, exigindo não apenas sua participação como também a interrelação dos agentes. $\mathrm{Na}$ forma ideal de narrativa transmídia, cada meio faz o que pode fazer da melhor maneira, inserindo uma história num filme ou divulgando-a pela televisão, sem que a apreciação de uma dependa da outra, vale dizer, não é preciso assistir ao filme para gostar dos quadrinhos e assim por diante. (JENKINS, 2009)

A narrativa transmídia migrou da área da Comunicação para o campo da Educação, sendo adotada como uma nova metodologia de ensino cujo conceito se manteve praticamente o mesmo. Para Gosciola e Versuti (2012), a narrativa transmídia é basicamente uma grande história, diferenciando-se de outras grandes histórias porque é dividida em partes. A história principal, a mais importante delas, não conta tudo, porque é complementada por histórias adicionais. De acordo com Raybourn (2014), na aprendizagem transmídia as mensagens comunicadas pela interação com cada meio devem reforçar a melhoria do desempenho, a reflexão e a mudança de comportamento. No atual contexto tecnológico, o modelo midiático é coproduzido por emissor-receptor, aqui professor e aluno, sendo que o conteúdo, a conectividade e a interatividade produzem efeitos de longo prazo (HANNA; ROHM; CRITTENDEN, 2011). Nesse sentido, as mídias sociais podem ser usadas para comentários e formação da história transmídia à medida que evolui. É uma oportunidade para explorar de forma mais ampla a história e permitir a formação de uma narrativa integrada e escalável a partir de diferentes visôes e plataformas para 
enriquecer a experiência da narrativa central. Assim, aproveita várias tendências das novas mídias, incluindo a comunicação em pares nas mídias sociais, a escalabilidade dos Cursos Online Abertos e Massivos (MOOCs) e o projeto de narrativas transmídia usado para entretenimento, publicidade e pelas indústrias de games para sustentar o engajamento com o público (RAYBOURN, 2014).

Jenkins (2007) acrescenta que, dentre as características das narrativas transmídia está a expansão em multiplataformas a estabelecer conexão entre os diversos fragmentos e, assim, a proporcionar ao usuário o senso de continuidade da história; a construção de um universo mutável, no qual a noçáo de espaço e de tempo é modificada pela exploração da narrativa a partir de novos elementos e personagens que adquirem vida própria; a subjetividade conectada às histórias secundárias, que evidenciam novas experiências narrativas e propóem novas perspectivas aos personagens; os dispositivos tecnológicos; e a interconexão das partes com o todo da história.

Para Gosciola (2011), o processo de transmidiação se dá a partir de uma narrativa inicial, com personagens definidos, seguindo para múltiplas tramas (desenvolvimento da vida de cada personagem) e para a divisão das tramas entre as mídias; por fim, a integração das tramas e dos meios de comunicação, buscando dotar o trabalho de unicidade e coerência. Nota-se que o uso de histórias, combinado com os recursos midiáticos, pode ser uma solução para integrar professores e alunos no processo de ensino-aprendizagem, de forma a desenvolver e compartilhar as informaçóes com maior efetividade. Blumenthal e Xu (2012) discutem o uso de conectores que podem potencialmente ligar a experiência dos participantes: a mitologia no contexto da narrativa - define os símbolos, marcos e conflitos culturais, as regras naturais e sobrenaturais que o autor introduz; o cânon - representa os elementos de mídia oficiais de um universo ficcional; a personagem - grande conector em toda a mídia, podendo se expressar como ator, personagem abstrato ou arquetípico; e o gênero - define e classifica elementos semelhantes em todas as histórias, atua como um esqueleto da narrativa.

Com base na conceituação de narrativa transmídia, percebe-se que a adoção dos dispositivos de criação e compartilhamento de informação vai de acordo com a cultura participativa, em uma era de convergência e possibilidades sem precedentes, para projetar experiências de aprendizagem. 
Trata-se de fatores que consideram as características do público adolescente que, nascida em meio a esse cenário midiático, já não aceita um ensino unidirecional e fechado a tantas oportunidades de melhoria.

\subsubsection{A importância de contar histórias}

Histórias são fundamentais em todas as culturas humanas: representam "o principal meio pelo qual se estrutura, compartilha e se compreende as experiências comuns" (JENKINS, 2009, p. 170); constituem uma propensão natural humana de se organizar as informaçóes (PADGETT; ALLEN, 1997); são usadas como um meio de auto expressão e uma maneira de fazer sentido para a vida (TOMKINS, 2009). Mesmo informalmente, em conversas diárias, o uso da técnica de contar histórias para comunicar ideias e expressar experiências é evidente. As crianças contam histórias para seus amigos imaginários; adultos contam suas histórias de infância para seus filhos; histórias são contadas entre colegas de trabalho sobre patrôes ou clientes; contam-se histórias para entreter, informar, educar, esclarecer e simplesmente emocionar (FITZGIBBON; WILHELM, 1998). As histórias oferecem mundos e experiências em que todos têm a opçáo de participar como cocriadores, todos contam e todos (se) escutam (SÁNCHEZ, 2013).

Para Sánchez (2013), a concepção de um projeto transmídia requer a construção de um mundo, ao invés de contar uma história. A equipe de criadores deve considerar o que será o mundo em que eles desenvolveráo as histórias, quais serão as principais linhas narrativas e plataformas que se encaixam no conjunto, para suscitar envolvimento/experiência nos espectadores/usuários/jogadores. Jenkins (2009) evidencia que a simples exposição da história em diferentes mídias não garante um caráter transmidiático à história, que deve ter seu uso combinado e integrado, não simplesmente transposto. Os elementos integrais da ficção devem ser sistematicamente apresentados pelos múltiplos canais para criar uma experiência unificada e coordenada de entretenimento.

Criar e/ou contar uma boa história é uma arte. Independentemente dos elementos que a narrativa contenha, do conflito que apresenta, do ambiente, tema, personagens ou meios pelos quais a comunicaçáo perpassa e como orienta o público entre eles, uma história deve conduzir a audiência, envolvê-la; fazer referências a elementos da cultura é uma sugestão para, 
durante o curso da narrativa, instigar a imaginação e a participação do público. Todos esses são aspectos essenciais para a promoção de um aprendizado efetivo.

\subsection{Aprendizado por meio da narrativa transmídia}

$\mathrm{O}$ avanço das tecnologias da informação e comunicação e todas as suas mudanças associadas têm aumentado o desafio no campo do ensino. As geraçốes $Y$ e $Z$, que nasceram nesse período transformacional, se deparam com modelos de aprendizagem pouco efetivos e que precisam ser revistos, alterados ou substituídos, principalmente devido às particularidades dessa nova Geração Z que, para Tapscott (2010), caracteriza-se pelo desejo de liberdade em tudo aquilo que faz, personalizando tudo à sua volta e considerando natural pesquisar e acessar informaçôes. Como os integrantes dessa geração cresceram em meio a experiências interativas, apresentam-se colaborativos, mas desejam respostas instantâneas. Para Rodrigues e Bidarra (2014), a ruptura dos pressupostos tradicionais de modelos educacionais tem impulsionado os educadores à exploração de diversos formatos de aprendizagem que possam atender às necessidades de um 'novo aluno' por meio da incorporação de novos tipos de inputs, consumo de mídia e práticas de produção, recursos globais e mudanças para um ambiente mais centrado no aluno. Se entendida a aprendizagem como um processo em que o aluno tem de ganhar autonomia progressivamente na direção e no controle de sua evolução, a utilização dos recursos deve responder plenamente a sua escolha pessoal. Desse modo, a evolução da tecnologia constitui recurso de apoio à aprendizagem que leva a situaçóes nas quais conteúdos e ferramentas estáo cada vez mais indistinguíveis, isto é, o futuro dos materiais de ensino será inseparável de seu suporte tecnológico (GARCÍA; LÓPEZ-PÉREZ, 2012).

A alternativa aqui tratada pela aprendizagem narrativa é uma forma significativa de reforço da imaginação dos alunos e da empatia (WOOD, 2014). Estudos em situaçóes do cotidiano têm demonstrado que a narrativa é um meio primário para resolução de problemas (JONASSEN; HERNANDEZ-SERRANO, 2002). Assim, a narrativa transmídia pode trazer temas que atraiam os alunos, unindo-os ao con- 
teúdo acadêmico e alinhando os Recursos Educacionais Abertos (REA) com atividades que estejam presentes nas suas atividades cotidianas. Gosciola e Versuti (2012) também classificam a narrativa transmídia como um REA, considerando-a como proposta diferenciada para contar histórias ampliadas que pressupóem intensa interatividade dos sujeitos envolvidos no processo. Kress (2003) salienta que a alfabetização moderna requer a capacidade de expressar ideias em uma ampla gama de sistemas de representação e significação, pois cada meio tem suas características inerentes, seus próprios sistemas de representação e estratégias de produção e organização do conhecimento. Os participantes, diante de múltiplas mídias, navegam nesses modos diferentes e, às vezes, conflitantes de representação e escolhem as melhores maneiras de expressar suas ideias, decidindo qual será a sequência narrativa e por quais plataformas optarão. (GOSCIOLA, 2011)

Jonassen e Hernandez-Serrano (2002) sugeriram três formas de apoiar o uso de histórias na aprendizagem: primeiro, elas podem ser usadas como exemplos de conceitos ou princípios ensinados por instrução direta; em segundo lugar, elas podem ser utilizadas como casos de problemas a serem resolvidos pelos alunos; e, em terceiro, as histórias podem ser utilizadas como aconselhamento para estudantes, para ajudá-los a aprender a resolver problemas. Segundo Rodrigues e Bidarra (2014), projetos transmídia mostram que a criação de mundos por histórias pode ser utilizada no cumprimento das metas educacionais, criam reforço e espalham o conteúdo de forma rica e fecunda para os alunos. A criação de um ambiente de aprendizagem transmídia pede uma redefinição urgente da aprendizagem curricular, na direçáo de tornar os processos de aprendizagem mais próximos dos contextos reais em que as pessoas socializam, se divertem e aprendem de maneira informal. Jonassen e Hernandez-Serrano (2002), por exemplo, com o fim de formar profissionais preparados para lidar com a complexidade das situaçóes no local de trabalho, propóe expô-los a histórias geradas no local de trabalho, de forma que os alunos reflitam sobre as semelhanças e diferenças entre a situação-problema e o caso/história dados, encontrem liçóes e solucionem problemas.

Outra proposta advinda da narrativa transmídia é a ideia de narração digital. Para Flottemesch (2013), trata-se de uma abordagem multimodal que traz a antiga arte de contar histórias para a vida usando a tecnolo- 
gia. Meadows (2003) acredita que a narração digital é a prática social de contar histórias que faz uso de câmeras digitais de baixo custo, ferramentas de criação não-lineares e computadores para criar histórias multimídia curtas, essencialmente pessoais e feitas para publicação na internet.

É importante perceber que a forma de incorporar narrativas no processo de ensino e aprendizagem é muito abrangente e pode ser adaptada à realidade de cada local, inserindo particularidades na metodologia e nos meios de comunicação para transportar a história. Resta saber se as metas educacionais são alcançadas com essa proposta. Por essa razão, para analisar o impacto do uso de narrativa transmídia no processo de ensino e aprendizagem, na sequência, abordam-se estudos empíricos encontrados na literatura, considerando alguns dos seus principais achados teóricopráticos.

\section{Resultados de estudos da literatura}

A partir da revisão da literatura em Educação em duas das principais bases de dados de estudos científicos: Web of Science e Periódicos

\subsection{O impacto do ensino com narrativa transmídia}

As tecnologias de informação e da comunicação têm, cada vez mais, se tornado o modelo de formação escolar, pois permitem que se avance de salas de aula onde os professores ensinam grupos de alunos da mesma forma, no mesmo tempo e com os mesmos mecanismos, para ambientes em que disponibilizam aos estudantes diversos recursos para o desenvolvimento de uma série de tarefas, acompanhando as necessidades específicas que surgem no processo. (GARCÍA; LÓPEZ-PÉREZ, 2012) 
Nesse sentido, a metodologia de narrativa transmídia ganha espaço. Os seres humanos parecem ter habilidade inata e predisposição para organizar e representar as suas experiências sob a forma de histórias (JONASSEN; HERNANDEZ-SERRANO, 2002). Para Fitzgibbon e Wilhelm (1998), histórias ajudam a comunicar o patrimônio literário e cultural, ao mesmo tempo que auxiliam os alunos a melhor desenvolver um senso de estrutura retórica. As vantagens mais citadas na literatura são benefícios afetivos, uma vez que a narração interessa aos alunos, reduz os filtros afetivos e permite que o aprendizado ocorra mais naturalmente dentro de uma comunicação interativa. Se novas ideias e conceitos são ensinados no contexto de uma história, a chance de o aluno entender provavelmente será maior, já que ele se depara com detalhes familiares no mesmo tempo em que se introduzem novos conceitos.

Segundo Kalogeras (2013), narrativa transmídia de entretenimento educativo é uma pedagogia crítico-criativa de investigação ativa e ação dialógica e criativa que cria lembranças, dá poder aos estudantes e valor para a comunidade. Essa aprendizagem transformadora induz os aprendentes a descobrir o significado do texto, recriar, refletir, refratar, reformular e reter a informação.

Menkhoff e Bengtsson (2012) defendem que as tecnologias de informação e comunicação (TIC) utilizadas pelos alunos da Geração Y, como parte de sua vida cotidiana, podem enriquecer significativamente a experiência desses alunos e produzir resultados de aprendizagem valiosos com base em aprendizagem combinada. Para isso, utilizar dispositivos de aprendizagem móvel traz emoção para a sala de aula e ajuda a capacitar os alunos, com dispositivos diários de comunicação com os quais os alunos estão familiarizados (MENKHOFF; BENGTSSON, 2012). Deve-se atentar, no entanto, para a qualidade da história. Em estudo desenvolvido por Sangalang, Quintero Johnson e Ciancio (2013), a qualidade foi o elemento mais importante para um jogo narrativo, pois a facilidade com que os eventos são construídos contribui para a fluidez e compreensão do mundo narrado. Dessa maneira o público se torna capaz de sintetizar elementos narrativos entre e dentre os vários formatos de mídia. Além disso, para Raybourn (2014), integral para o projeto de campanhas transmídia e medição da aprendizagem é a capacidade de rastrear a interação, feedback e 
conteúdo gerado pelo usuário por meio da mineração e atividade de dados de mídia social.

O estudo de Sangalang, Quintero Johnson e Ciancio (2013) investigou o envolvimento do público com um jogo interativo desenhado como parte de um esforço mais amplo de narrativa transmídia, criado com estrutura narrativa e objetivo de encorajar o consumo de leite. Além disso, foram examinados os fatores que influenciaram o envolvimento: diversão e frustração; foi demonstrado que a compreensão da narrativa está relacionada ao sentimento de envolvimento, das experiências dos participantes (transportation). O processamento do público se dá em dois níveis distintos: a compreensão dos eventos da história a partir de um fio narrativo e a sintetização dos fios narrativos dentro do mundo maior da narrativa. Embora tenha sido um estudo exploratório, foi uma tentativa de conceituar e avaliar o envolvimento com a narrativa em campanhas de narrativa transmídia de entretenimento educativo.

Menkhoff e Bengtsson (2012) integraram dispositivos de aprendizagem móveis - telefones celulares, sites de compartilhamento de fotos, wikis, podcasts e excursóes a pé com os alunos - como ferramentas educacionais de um curso de graduação em empreendedorismo chinês. As experiências sugerem que os recursos integrados de aprendizagem online centradas nos alunos são fundamentais para facilitar o compartilhamento de informação e conhecimento entre colegas. $\mathrm{O}$ estudo sugere que um método de ensino que póe ênfase nas tecnologias móveis de aprendizagem num contexto pedagógico que combina mini palestras, apresentaçóes dos alunos, passeios orientados e visitas de campo claramente ajuda a promover a aprendizagem.

O estudo de Wood (2014) tratou da imaginação, particularmente da teoria da resposta do leitor, na aprendizagem por meio da narrativa na educação enfermeira. A imaginação histórica, com base na história de uma enfermeira do passado, deu suporte para descrever as respostas dos leitores de estudantes de pós-graduação de enfermagem, ilustrando como a aprendizagem narrativa pode se estender para a prática. Essa análise demonstrou que o uso de narrativas históricas envolve a imaginação dos alunos, fazendo-os discutir, questionar suposiçóes e traduzir o passado para o presente. Sendo assim, a teoria da resposta do leitor oferece uma base valiosa para a aprendizagem narrativa. 
Niemi et al. (2014) apresentaram como a narração digital (digital storytelling) pode criar ambientes virtuais de aprendizagem quando usada para o aprendizado de habilidades e competências necessárias na futura vida profissional dos alunos. Dessa forma, os alunos têm um papel central na exploração e construção de conhecimentos por meio de diferentes tipos de ferramentas, atuando como produtores de conteúdo e consumidores. Para Niemi et al. (2014), ao planejar e fazer histórias digitais, os alunos tornam-se conscientes de seus próprios conhecimentos e experiências, podendo refletir sobre eles e compartilhá-los. No mesmo sentido, o trabalho de Flottemesch (2013), que usou a narrativa digital como instrumento pedagógico para melhorar os resultados de aprendizagem dos estudantes, proporcionando a eles uma oportunidade de estarem envolvidos em sua aprendizagem, uma vez que a capacidade de personalizar histórias com imagens, narração pessoal, vídeo, animação, artefatos e música suporta um nível mais profundo de compreensão e significado.

Tan, Lee e Hung (2014) também implementaram a narração digital, por meio da abordagem de histórias edu-tainment (entretenimento educativo) aplicada à disciplina de Ciência de uma sala de aula de quinta série. Essa classe de estruturação narrativa considera que os personagens dentro da narrativa seriam introduzidos em um contexto problemático, e gastariam grande parte da história buscando uma solução que levasse a narrativa ao clímax, onde o personagem principal descobriria um conceito que resolve o problema na hora certa (TAN; LEE; HUNG, 2014). Nesse sentido, os alunos tiveram que desenhar uma história que comunicou um conceito científico embutido numa estrutura narrativa, na qual personagens tiveram que experimentar os efeitos do conceito. Assim, a qualidade da história foi indicada pela compreensão do conceito científico dos alunos. Essa metodologia mostrou-se viável, mas ainda há necessidade de estudá-la em maior profundidade. O diferencial foi a construção das histórias contendo os elementos de uma narração junto com as informaçóes da disciplina, instigando os alunos a refletir, interpretar e aprender os dados para criar a história.

Agosto (2013) procurou analisar impressões do desempenho da narraçáo oral de crianças em idade escolar, como revelado pelas respostas de seus desenhos, escritos e falas, verificando os tipos de benefícios educacionais e sociais/emocionais que as crianças podem obter ao experimentar a 
narração oral, detectando cinco tipos: habilidades de pensamento crítico, criatividade, ativa participação/engajamento na aprendizagem, competências na alfabetização e habilidades de pensamento narrativo. Foram detectados também dois tipos de benefícios sociais/emocionais: autoexploração e competências interpessoais. Apesar desse potencial, segundo Pietschmann, Völkel e Ohler (2014), o conteúdo transmídia apresenta limitaçóes para o público infantil: sua estrutura narrativa complexa não pode simplesmente ser adaptada para crianças. Do ponto de vista da psicologia do desenvolvimento, às crianças mais jovens falta a capacidade dos adultos de usar, entender e participar de franquias de transmídia.

\subsection{Engajamento dos alunos na educaçáo}

A sociedade está mudando de uma 'Era da Informação' para uma 'Era do Engajamento' na qual a narrativa (storytelling) está sempre presente (KALOGERAS, 2013). Para Taylor e Parsons (2011), o engajamento dos alunos tornou-se tanto um processo estratégico de aprendizagem quanto um resultado de prestação de contas em si mesmo. De acordo com Massarolo e Mesquita (2013), no ambiente escolar a migração dos jovens estudantes pelos espaços caracterizados pela mobilidade, interatividade e colaboração reforça a emergência de uma nova cultura, baseada na participação nos processos criativos das histórias. Por essas razóes, a aprendizagem transmídia permite experiências de aprendizagem sustentadas que resultam em mudança de comportamento mensurável, que pode ser física e explícita, intelectual, de atitude, ou uma combinação dessas formas.

Contudo, alcançar as metas de aprendizagem por meio da aprendizagem transmídia requer pensamento sistêmico e planejamento (RAYBOURN, 2014). $\mathrm{Na}$ análise da literatura sobre as estratégias comuns para melhorar o engajamento dos alunos na aprendizagem, feita por Taylor e Parsons (2011), um padrão de práticas foi recomendado, repetido e, então, sintetizado nas seguintes categorias: interação; exploração; relevância; multimídia; instrução e avaliação para a aprendizagem, que apela para que os professores utilizem práticas de avaliaçáo formativa para monitorar o sucesso do aluno e se envolver em conversas regulares de partilha com eles. Segundo a pesquisa dos autores, é preciso mudar a forma de ensinar, 
bem como o que se ensina, para engajar os estudantes, adotando uma pedagogia construtivista que requer relaçóes respeitosas e ambientes de aprendizagem seguros, especialmente na relação professor-aluno, que deve mudar de perito-discípulo para a aprendizagem colaborativa.

Esforços no sentido de engajar o aluno são percebidos nas pesquisas acadêmicas, por exemplo, no estudo de Tan, Lee e Hung (2014) que propôs aos estudantes criar uma narrativa edu-tainment, para a qual foi necessário compreender o conceito científico, construir uma narrativa coerente com situaçóes problemáticas plausíveis para o cenário e personagens; ao mesmo tempo, propunha preparar uma situação na qual o conceito científico poderia significativamente resolver o problema sem parecer demasiado óbvio. Em muitos aspectos, este foi concebido como um exercício para provocar os alunos, engajá-los e demonstrar a sua competência na construção narrativa e nos conceitos científicos.

De acordo com Raybourn (2014), para sustentar o engajamento com o público a aprendizagem transmídia aproveita várias tendências das novas mídias, incluindo a comunicação em pares nas mídias sociais, a escalabilidade do curso online maciçamente aberto (MOOCs) e o projeto de narrativas transmídia usado para entretenimento, publicidade e pelas indústrias de jogos comerciais. Como no estudo de Tomkins (2009), no qual os alunos foram solicitados a desenvolver histórias para guiá-los nos estágios de aprendizagem, completando os exercícios em uma base semanal, a fim de traçar o seu progresso e demonstrar sua jornada, com o objetivo final de alcançar a fase da aprendizagem transformadora. A definição de Tomkins (2009) para aprendizagem transformadora implica mudança de comportamento decorrente das reflexóes críticas e ações planejadas. A técnica de contar histórias vem, de alguma forma, para ajudar os alunos a enfrentar esse desafio, pois fornece suporte para eles construirem seu próprio significado oriundo do conhecimento que estão adquirindo, equipando-os com um processo que fornece um modelo para a aprendizagem reflexiva.

Vários elementos da transmídia podem ser usados nos projetos que utilizam experiências para criar engajamento e transformam os alunos em participantes ativos da aprendizagem (RODRIGUES; BIDARRA, 2014). A promoção do engajamento envolve qualidades motivacionais, incluindo experiências emocionais positivas tais como diversão, aspiraçôes, inspiraçôes, entusiasmo dos alunos e compromisso ou capacidade de persistir em 
um trabalho para uma tarefa de aprendizagem. A tecnologia é uma ferramenta que motiva os alunos e fornece cenários em que eles podem fazer suas próprias contribuiçôes (NIEMI et al., 2014). Essa participação ativa de alunos e educadores é chamada, por Rodrigues e Bidarra (2014), de aprendizagem conectada, que aborda os desafios da falta de conexão entre educação formal e contextos sociais dos alunos, bem como a necessidade de reforçar a participação cívica.

\section{Discussáo das análises a partir da literatura em Educação}

Muitas das pesquisas que tratam da narrativa transmídia envolvem estudos de caso, estudos exploratórios com relatos de tentativas e experiências pedagógicas que incorporam elementos da narrativa transmídia. Nota-se que, embora a técnica narrativa seja antiga, principalmente a oral, a união com a transmídia é inovadora. Há, contudo, necessidade de estudos e experiências relacionados ao processo de ensino e aprendizagem envolvendo a narrativa transmídia, considerando principalmente a constante renovação das tecnologias de informação e de comunicação que afetam a cultura, o comportamento humano e, por consequência, a forma de facilitar o ensino das geraçôes $\mathrm{Y}$ e $\mathrm{Z}$ nas escolas, universidades e demais instituiçóes de ensino.

Uma questão a ser refletida é que muitos estudos encontrados na pesquisa bibliográfica tratam ou da narrativa ou da transposição por várias mídias, ou seja, há certa dificuldade na implantação de uma metodologia com base em histórias que sejam contadas em pedaços, fragmentados mas complementares, como emprego de diferentes meios de comunicação. Da mesma forma, não há estudos comparativos dessa metodologia com os públicos infantil, adolescente e adulto; o uso de histórias em sala de aula causa o mesmo efeito em crianças e adolescentes? Os esforços de adotar a metodologia de narrativa transmídia parecem surtir mais efeitos sob o público infantil; estudos envolvendo adolescentes focam na utilização de mídias digitais para a compreensáo do conteúdo proposto, sem haver uma história permeando essas diferentes mídias. Dessa forma, o próprio conceito de narrativa transmídia é usado de forma equivocada. 
Uma questão relevante é que os estudos levantados são pontuais, seccionais e não há uma experiência de uso das narrativas em sala de aula longitudinal. Será que essa proposta se mantém com a mesma efetividade ao longo do tempo? Nota-se também que o uso de narrativas pode ser combinado com outras metodologias como a resoluçáo de problemas e estudo de caso, unindo a facilidade do ser humano de identificar e interpretar histórias e a compreensão de problemas com base em narrativas. Essa questáo mostrou-se bem positiva para os resultados almejados.

Tecnologia, informação, multitarefa, conteúdo, conectividade, interatividade, colaboração - essas são palavras-chave que representam, em parte, uma campanha de narrativa transmídia e que precisam estar presentes em sala de aula para melhorar a qualidade do processo de ensino e aprendizagem e engajar os adolescentes da atualidade. Ambientes de aprendizagem mediados por tecnologia tornaram-se mais interativos, sincrônicos e flexíveis, capazes de conectar diferentes recursos digitalizados e ferramentas para a criação de conhecimento (NIEMI et al., 2014). É importante considerar que a essência da narrativa transmídia é de como todas as peças se encaixam para formar um todo que é maior do que a soma de suas partes.

\section{Consideraçóes finais}

O estudo atingiu o seu objetivo de verificar a efetividade do uso da estratégia de narrativa transmídia para o engajamento de adolescentes no processo de ensino e aprendizagem. A pesquisa bibliográfica demonstra que o uso de narrativa transmídia tem gerado resultados bem positivos para o aprendizado e engajamento dos alunos na temática proposta, adotando um ensino em que os professores disponibilizam aos estudantes diversos recursos para o desenvolvimento de uma tarefa, disseminando conhecimento, prática e caminhos para a coaprendizagem. No final, conhecimento tem de ser criatividade, inovação e imaginação.

O fator mais importante é que os alunos adquiram a capacidade de aprender ao longo da vida e que a educação forneça as habilidades e ferramentas mentais para capacitá-los a isso. Os alunos devem desenvolver a capacidade de fazer perguntas e trabalhar de forma independente, 
mas também colaborativa. A vida está cada vez mais ligada à tecnologia; ambientes de aprendizagem estão continuamente mudando e tecnologias de informação e comunicação oferecem muitas novas oportunidades de aprendizagem. E, se a educação é uma forma de 'transformar a sua alma', e mesmo que não seja, histórias deixam almas falar e histórias podem transformar almas. Os seres humanos devem contar suas histórias porque elas reforçam quem eles são.

Futuras pesquisas envolvendo a narrativa transmídia em experimentos em sala de aula com diferentes faixas etárias de alunos e utilizando de diferentes disciplinas e conteúdos serão importantes para averiguar se a efetividade dessa metodologia será mantida, alterada ou potencializada. Uma reforma curricular no sentido de aproximar a realidade dos alunos em sala de aula e permitir que o conhecimento seja construído em conjunto é uma necessidade contemporânea e, por isso, o uso de histórias em conjunto com as tecnologias de informação e comunicação precisa ganhar destaque.

\section{Nota}

1 Artigo similar foi publicado na revista Creative Education, v. 07, n. 07(2016), com título "Use of transmedia storytelling for teaching teenagers".

\section{Referências}

AGOSTO, D. E. If I had three wishes: The educational and social/emotional benefits of oral storytelling. Storytelling, Self, Society, v. 9, n. 1, p. 53-76, 2013. <http://dx.doi. org/10.13110/storselfsoci.9.1.0053>.

BLUMENTHAL, H.; XU, Y. The Ghost Club Storyscape: designing for transmedia storytelling. IEEE Transactions on Consumer Electronics, v. 58, n. 2, p. 190-196, 2012. <http://dx.doi.org/10.1109/TCE.2012.6227412>.

CERETTA, S. B.; FROEMMING, L. M. Geração Z: compreendendo os hábitos de consumo da geração emergente. Revista Eletrônica do Mestrado em Administração da Universidade Potiguar - RAUnP, v. 3, n. 2, p. 15-24, 2011. Disponível em: <https:// repositorio.unp.br/index.php/raunp/article/view/70/91>. Acesso em: 21 ago. 2017. 
DEL MAR GRANDÍO-PÉREZ, María. El transmedia en la enseñanza universitaria. Análisis de las asignaturas de educación mediática en España (2012-2013). Palabra Clave, v. 19, n. 1, p. 85-104, 2016.

FITZGIBBON, H. B.; WILHELM, K. H. Storytelling in ESL/ EFL classrooms. TESL Reporter, v. 31, n. 2, p. 21-31, 1998. Disponível em: <https://fluencyms.weebly.com/ uploads/5/3/0/9/53092285/storytelling.pdf>. Acesso em: 21 set. 2017.

FLEMING, Laura. Expanding Learning Opportunities with Transmedia Practices:" Inanimate Alice" as an Exemplar. Journal of Media Literacy Education, v. 5, n. 2, p. 370-377, 2013.

FLOTTEMESCH, K. Learning through narratives: the impact of digital storytelling on intergenerational relationships. Academy of Educational Leadership Journal, v. 17, n. 3, p. 53-60, 2013. Disponível em: <https://www.questia.com/library/ journal/1P3-2999118561/learning-through-narratives-the-impact-of-digital>. Acesso em: 23 out. 2017.

GAMBARATO, R. R. Transmedia project design: theoretical and analytical considerations. Baltic Screen Media Review, v. 1, p. 80-100, 2013. <http://dx.doi. org/10.1515/bsmr-2015-0006>.

GARCÍA, I.; LÓPEZ-PÉREZ, C. La función de los recursos de aprendizaje en la universidad. In: OKADA, A., ed. Open educational resources and social networks: colearning and professional development. London: Scholio Educational Research \& Publishing, 2012, p.122-133. Disponível em: <http://oro.open.ac.uk/39236/1/OERcompleto-final-05-07.pdf>. Acesso em: 24 out. 2018.

GOSCIOLA, V. Narrativa transmídia: a presença de sistemas de narrativas integradas e complementares na comunicação e na educação. Quaestio, Sorocaba, SP, v. 13, n. 2, p. 117-126, 2011. Disponível em: <http://periodicos.uniso.br/ojs/index.php/quaestio/ article/view/692>. Acesso em: 20 set. 2018.

GOSCIOLA, V.; VERSUTI, A. Narrativa transmídia e sua potencialidade na educação aberta. In: OKADA, A., ed. Open educational resources and social networks: colearning and professional development. London: Scholio Educational Research \& Publishing, 2012, p. 236-242. Disponível em: <http://oro.open.ac.uk/39236/1/OER-completofinal-05-07.pdf>. Acesso em: 24 jan. 2019.

HANNA, R.; ROHM, A.; CRITTENDEN, V. L. We're all connected: The power of the social media ecosystem. Business Horizons, v. 54, n. 3, p. 265-273, 2011.

JENKINS, H. Cultura da convergência. São Paulo: Aleph, 2009.

JENKINS, H. Transmedia storytelling. Confessions of an Aca-fan. The Oficial Weblog of Henry Jenkins, 2007. Disponível em: http://www.henryjenkins.org/2007/03/ transmedia_storytelling_101.html. Acesso em: 29 jul. 2018. 
JENKINS, H.; PURUSHOTMA, R.; WEIGEL, M.; CLINTON, K.; ROBISON, A. J. Confronting the challenges of participatory culture: media education for the 21 st century, The MIT Press Cambridge, Massachusetts, 2009.

JONASSEN, D. H.; HERNANDEZ-SERRANO, J. Case-based reasoning and instructional design using stories to support problem solving. Educational Technology Research and Development, v. 50, n. 2, p. 65-77, 2002. <http://doi.org/10.1007/ BF02504994>.

KALOGERAS, S. Storytelling: an ancient human technology and critical-creative pedagogy for transformative learning, International Journal of Information and Communication Technology Education, v. 9, n. 4, p. 113-122, 2013. <http://doi.org /10.4018/ijicte.2013100108.>

KINDER, M. Playing with power in movies, television, and video games: from Muppet Babies to Teenage Mutant Ninja Turtles. Berkeley: University of California Press, 1991.

KRESS, G. Literacy in the New Media Age. New York: Routledge, 2003.

MASSAROLO, J. C.; MESQUITA, D. Narrativa transmídia e a educação: panorama e perspectivas. Revista Ensino Superior Unicamp, p. 34-42, 2013. Disponível em: <https:// www.revistaensinosuperior.gr.unicamp.br/artigos/narrativa-transmidia-e-a-educacaopanorama-e-perspectivas >. Acesso em: 14 out. 2018.

MEADOWS, D. Digital Storytelling: research-based practice in new media. Visual Communication, v. 2, n. 2, p.189-193, 2003. Disponível em: <http://vcj.sagepub.com/ content/2/2/189.extract>. Acesso em: 20 nov. 2018.

MENKHOFF, T.; BENGTSSON, M. L. Engaging students in higher education through mobile learning: lessons learnt in a chinese entrepreneurship course. Educ Res Policy Prac, v. 11, p. 225-242, 2012. Disponível em: <https://www.learntechlib. org/p/71973/>. Acesso em: 20 nov. 2018.

NIEMI, H.; HARJU, V.; VIVITSOU, M.; VIITANEN, K.; MULTISILTA, J.; KUOKKANEN, A. Digital storytelling for 21st-century skills in virtual learning environments. Creative Education, v. 5, p. 657-671, 2014. <http://dx.doi.org/10.4236/ ce.2014.59078>.

PADGETT, D.; ALLEN, D. Communicating experiences: a narrative approach to creating service brand image. Journal of Advertising, v. 26, n. 4, Services Advertising, p. 49-62, 1997. Disponível em: <http://www.jstor.org/stable/4189050?origin=JSTORpdf\&seq=1\#page_scan_tab_contents>. Acesso em: 25 nov. 2018.

PIETSCHMANN, D.; VÖLKEL, S.; OHLER, P. Limitations of transmedia storytelling for children : a cognitive developmental analysis. International Journal of Communication, v. 8, p. 2259-2282, 2014. Disponível em: <http://ijoc.org/index.php/ ijoc/article/viewFile/2612/1205>. Acesso em: 25 nov. 2018. 
RAYBOURN, E. M. A new paradigm for serious games: transmedia learning for more effective training and education. Journal of Computational Science, v. 5, p. 471-481, 2014. <https://doi.org/10.1016/j.jocs.2013.08.005>

RODRIGUES, P.; BIDARRA, J. Transmedia storytelling and the creation of a converging space of educational practices, International Journal of Emerging Technologies in Learning - iJET, v. 9, n. 6, 2014. <http://dx.doi.org/10.3991/ijet.v9i6.4134>.

SÁNCHEZ, C. C. Narrativas transmedia nativas: ventajas, elementos de la planificación de un proyecto audiovisual transmedia y estudio de caso. Historia y Comunicación Social, v. 18, n. Esp., p. 561-574, 2013. <http://dx.doi.org/10.5209/ rev_HICS.2013.v18.44349>.

SANGALANG, A.; QUINTERO JOHNSON, J. M.; CIANCIO, K. E. Exploring audience involvement with an interactive narrative: implications for incorporating transmedia storytelling into entertainment-education campaigns. Critical Arts, v. 27, n. 3, p. 127-146, 2013. <https://doi.org/10.1080/02560046.2013.766977>.

TAN, M.; LEE, S.-S.; HUNG, D. W. L. Digital storytelling and the nature of knowledge, Journal Education and Information Technologies, v. 19, p. 623-635, 2014. <http://dx.doi.org/10.1007/s10639-013-9280-x>.

TAPSCOTT, D. A hora da geração digital: como os jovens que cresceram usando a Internet estão mudando tudo, das empresas aos governos. Rio de Janeiro: Agir Negócios, 2010.

TAYLOR, L.; PARSONS, J. Improving student engagement. Current Issues in Education, v. 14, n. 1, 2011. Disponível em: <http://cie.asu.edu/ojs/index.php/cieatasu/ article/viewFile/745/162>. Acesso em: 6 dez. 2018.

TOMKINS, A. “It was a great day when...”: an exploratory case study of reflective learning through storytelling, Journal of Hospitality, Leisure, Sport and Tourism Education, v. 8, n. 2, p. 123-131, 2009. <http://dx.doi.org/10.3794/johlste.82.198>.

WOOD, P. J. Historical imagination, narrative learning and nursing practice: graduate nursing students' reader-responses to a nurse's storytelling from the past. Nurse Education in Practice, v. 14, p. 473-478, 2014. <http://dx.doi.org/10.1016/j. nepr.2014.05.001>.

Recebido em I8 dez. 2017 / Aprovado em 20 fev. 2019

\section{Para referenciar este texto:}

VIEIRA, A. M. D. P.; MUNARO, A. C. A narrativa transmídia no processo de ensino e aprendizagem de adolescentes. EccoS - Revista Cientifica, São Paulo, n. 48, p. 317-337. jan./mar. 2019. Disponível em: <https://doi.org/I0.5585/EccoS.n48.8182>. 
